\title{
QUALIDADE DO MEXILHÃO Perna perna SUBMETIDO AO PROCESSO COMBINADO DE COCÇÃO, CONGELAMENTO E ARMAZENAMENTO
}

\author{
DANIELA CORDEIRO* \\ TATIANA GISELE GUIMARÃES LOPES* \\ MARILIA OETTERER** \\ ERNANI PORTO*** \\ JULIANA ANTUNES GALVÃO****
}

\begin{abstract}
Mexilhões da espécie Perna perna, cultivados e comercializados no município de Ubatuba (SP), foram submetidos ao processamento por cocção, congelamento e armazenamento. Foram determinados o ponto de congelamento, a velocidade de congelamento a as curvas de congelamento do mexilhão semi-desconchado, sendo também avaliada a qualidade microbiológica e físicoquímica do produto. O beneficiamento do mexilhão iniciouse com a cocção por imersão em água a ebulição por 10 min (permitindo a retirada das conchas), sendo então congelados individualmente (Individually Quick Frozen) pelo método de congelamento por ar forçado. A curva de congelamento do mexilhão apresentou forma geral típica com o ponto de congelamento na faixa de zero a $-1,5^{\circ} \mathrm{C}$ e a velocidade de congelamento variou de 2 a $3,3 \mathrm{~cm} / \mathrm{h}$, conforme a disposição dentro da câmara de congelamento. Não houve alteração na qualidade físico-química das amostras após a cocção, congelamento e armazenamento. Em relação à qualidade microbiológica, todas as amostras de mexilhão in natura atenderam aos padrões microbiológicos estabelecidos pela legislação brasileira. Salmonella sp e Vibrio parahaemolyticus não foram isolados em nenhuma das amostras de mexilhões in natura, cozidos, congelados e armazenados. O tratamento térmico controlou os coliformes fecais, bem como reduziu os valores de contagem de coliformes totais, Staphylococcus aureus e psicrotróficos. O mexilhão congelado não apresentou S.aureus e a contagem de coliformes totais no produto foi menor após cocção. Concluiu-se que o beneficiamento do mexilhão pelo processo combinado de cocção, congelamento e armazenamento assegura a qualidade físico-química e microbiológica do produto, podendo ser adotado como padrão para industrialização.
\end{abstract}

PALAVRAS-CHAVE: MEXILHÃO - COCÇÃO; VELOCIDADE DE CONGELAMENTO; CURVA DE CONGELAMENTO; ARMAZENAMENTO CONGELADO.

* Zootecnista, Mestre em Ciência e Tecnologia de Alimentos, Escola Superior de Agricultura "Luiz de Queiroz", Universidade de São Paulo (ESALQ/USP), Piracicaba, SP (e-mail: danicord@fea.unicamp.br).

** Professora Titular, Livre Docente em Ciência e Tecnologia de Alimentos, Departamento de Agroindústria, Alimentos e Nutrição, ESALQ/USP, Piracicaba, SP (e-mail: moettere@esalq.usp.br).

*** Professor, Doutor em Ciências de Alimentos, Departamento de Agroindústria, Alimentos e Nutrição, ESALQ/USP, Piracicaba, SP (e-mail: eporto@esalq.usp.br).

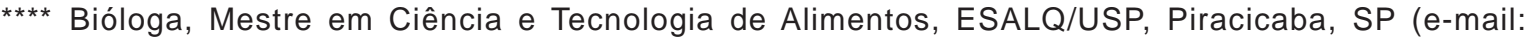
jagalvao@esalq.usp.br). 


\section{INTRODUÇÃO}

A criação de mexilhões ou mitilicultura constitui uma das atividades mais produtivas da aqüicultura, alcançando até $30 \mathrm{t}$ de carne por ha/ano, o que representa a maior produção obtida com modalidade de criação não-sujeita a alimentação artificial. Além de diversos aspectos biológicos favoráveis, outros fatores como o baixo custo das instalações, facilidade de manejo e localização dos cultivos no mar contribuíram para a expansão mundial dessa atividade nos últimos anos. Segundo dados da FAO, a produção de mexilhões cultivados alcançou 1.860.249 t/ano em 2004, sendo a China o maior produtor mundial. Países como a Espanha, França, Estados Unidos e Canadá destacam-se também como grandes produtores de mexilhões. O Brasil produziu no mesmo período $19.000 \mathrm{t}$ de moluscos (FAO, 2007).

Em 2005, a produção de mexilhões em Santa Catarina alcançou 12.234 t, representando crescimento de $24,8 \%$ em relação a 2004 (EPAGRI, 2007).

Segundo informações da Associação dos Mitilicultores do Estado de São Paulo (AMESP), a produção de mexilhões no Litoral Norte é de cerca de 100 t/ano. A atividade está em crescimento, porém apresenta problemas organizacionais. Na região não há entreposto que receba a produção e nem ponto de beneficiamento. O Serviço de Inspeção Federal (SIF) do Ministério de Agricultura Pecuária e Abastecimento não contempla a área de cultivo e sim o estabelecimento, o que faz com que o produtor não possa transportar o seu produto legalmente para outros mercados consumidores. A ausência de fiscalização implica em risco à saúde pública e a clandestinidade inviabiliza a comercialização com marketing, mantendo a demanda baixa até mesmo na região litorânea (ASSUMPÇÃO, 1999).

Os moluscos (lulas, ostras e mexilhões) e os crustáceos (camarão), apesar de constituírem os principais grupos de organismos marinhos explorados como alimento no Brasil não são processados pela indústria nacional. Esses recursos podem representar fonte alimentar com alto valor protéico (FURTADO, 2000).

A armazenagem e estocagem dos moluscos são limitadas quando comercializados in natura (as valvas ocupam muito espaço) e o beneficiamento só ocorre em pequena parcela da matériaprima. Há tendência de se promover o crescimento da capacidade de armazenamento e estocagem desses produtos, buscando adequá-los aos novos processos de beneficiamento e garantindo a qualidade que o mercado exige (BEIRÃO, TEIXEIRA e MEINERT, 2000).

O mexilhão apresenta pronunciada variação sazonal na composição de sua carne, com maior rendimento na época de desova. O valor energético da sua carne é de $80 \mathrm{Kcal} / 100 \mathrm{~g}$ próximo ao dos peixes magros como a merluza (Merlucius merlucius), enquanto que outros moluscos e ostras apresentam em média $76 \mathrm{Kcal} / 100 \mathrm{~g} \mathrm{e} 44 \mathrm{Kcal} / 100 \mathrm{~g}$, respectivamente. Contém de 1 a $7 \%$ de glicogênio, teor elevado em relação às outras carnes e peixes em que esse carboidrato ocorre em baixa proporção. A fração protéica do pescado situa-se na faixa de $8,4 \%$ a $17 \%$, já para mariscos e ostras os valores médios são de 13\% e 6\%, respectivamente (SILVA, 2000).

Os padrões de qualidade do pescado e derivados estão baseados na análise de compostos como, Bases Voláteis Totais (BNVT) e Trimetilamina (TMA). O Regulamento de Inspeção Industrial e Sanitária de Produtos de Origem Animal (RIISPOA) do Ministério da Agricultura preconiza níveis de Bases Voláteis Totais inferiores a $30 \mathrm{mg} \mathrm{N} / 100 \mathrm{~g}$ em carnes para atestar frescor ao produto e para o pH níveis inferiores a 6,8 na parte externa e 6,5 na parte interna da carne (BRASIL,1980). Determinam frescor também, a reação negativa para gás sulfídrico e de indol, com exceção de alguns crustáceos com limite máximo de $4 \mathrm{mg} \mathrm{N} / 100 \mathrm{~g}$. Substâncias nitrogenadas não-protéicas como inosina, ribose, uréia e óxidos de trimetilamina com baixo peso molecular resultam da ação enzimática no músculo do pescado. Constituem substratos preferenciais para a utilização e decomposição microbiana, que provocam profundas alterações organolépticas no pescado (BEIRÃO, TEIXEIRA e MEINERT, 2000; IAL, 1985). 
Processos de conservação mediante refrigeração e congelamento, bem como processamentos térmicos podem alterar fisicamente as carnes e promover alterações em vários componentes. $\mathrm{O}$ processo de refrigeração (temperaturas entre $-1^{\circ} \mathrm{C}$ e $10^{\circ} \mathrm{C}$ ) não apresenta ação esterilizante, apenas retarda as atividades microbianas já existentes e impede o surgimento de novos agentes deteriorantes. A refrigeração possibilita a manutenção da qualidade nutritiva da carne, bem como promove a manutenção dos caracteres sensoriais. O congelamento, por empregar temperaturas mais baixas que a refrigeração, prolonga o tempo de conservação da carne. As temperaturas utilizadas diminuem ou paralisam a deterioração causada por microrganismos, enzimas ou agentes químicos. Além disso, o congelamento constitui um dos melhores métodos para manter a cor, o aroma e a aparência do alimento (BEN, 1999).

No geral, o valor nutritivo dos alimentos submetidos ao congelamento permanece integralmente conservado. Inclusive, em termos comparativos com os outros métodos de conservação, o congelamento é o que mais preserva a integridade dos nutrientes. Os nutrientes mais sensíveis ao armazenamento congelado, presentes no pescado são a tiamina e o ácido fólico (INSTITUTO INTERNACIONAL DEL FRIO, 1990; OETTERER, 2002)

A contagem de microrganismos viáveis em crustáceos e moluscos refere-se comumente ao animal inteiro, ou à carne separada da concha, que geralmente alcançam populações entre $10^{3} \mathrm{e}$ $10^{7} \mathrm{UFC} / \mathrm{g}$. Já foi estabelecida relação entre cargas microbianas altas ou baixas e a procedência dos animais de águas frias ou quentes. Os moluscos, devido ao seu tipo de vida sedentária, apresentam contagens bacterianas que refletem o estado microbiológico das águas de cultivo, cujas contagens aumentam nos meses de verão (ICMSF, 1988; JAY, 1994).

O beneficiamento do mexilhão inicia-se com a cocção, que permite a retirada das conchas e a ligeira pasteurização da carne. Após lavagem, o mexilhão é cozido durante 6 minutos na água em ebulição ou no vapor a $100^{\circ} \mathrm{C}$, ou por 4 minutos em vapor a $115^{\circ} \mathrm{C}$. Uma vez cozido e descascado, a carne pode ser resfriada e empacotada para ser comercializada ou destinada à industrialização (ESPÍNOLA e DIAS, 1980).

O uso do frio como método de preservação de alimentos retarda a ação de agentes deteriorantes e diminui as reações químicas. Porém, a qualidade da matéria-prima é de fundamental importância para a obtenção de produto com alta qualidade (CARNEIRO, 1999).

O congelamento permite a conservação dos alimentos por longo período, inclusive aqueles com alta atividade de água. $\mathrm{O}$ tempo de congelamento a $-35^{\circ} \mathrm{C}$ por $5 \mathrm{~h}$ caracteriza o congelamento rápido e ideal para manter a textura e a qualidade do alimento, pois quando congelado lentamente a $-18^{\circ} \mathrm{C}$ parte da água se manterá líquida e diminuirá o seu tempo de vida útil para 6 meses. Uma vez congelados, os produtos devem ser mantidos em temperatura entre -18 a $-20^{\circ} \mathrm{C}$, aproximadamente, até o momento de sua utilização pelo consumidor. Assim, não deve ocorrer nenhuma quebra na cadeia de frio durante o transporte, armazenamento nos pontos de venda e na residência do consumidor. A vida útil desses produtos supera 12 meses, quando mantidos em câmaras a $-35^{\circ} \mathrm{C}$ (FURTADO, 2000).

Em temperaturas próximas de $-3^{\circ} \mathrm{C}$ cessa a multiplicação de algumas bactérias e leveduras. Os microorganismos que poderiam deteriorar o pescado não se desenvolvem abaixo de $-10^{\circ} \mathrm{C}, 0$ crescimento da maioria dos microrganismos é bloqueado a $-12^{\circ} \mathrm{C}$ e cerca de $90 \%$ da água de constituição do pescado encontra-se congelada a $-20^{\circ} \mathrm{C}$ (CLUCAS, 1981; GEROMEL e FORSTER, 1982).

O congelamento $\mathrm{a}-5^{\circ} \mathrm{C}$ permite que 70 a $75 \%$ da água do pescado congele, sendo a água restante congelada abaixo de $-5^{\circ} \mathrm{C}$. Assim, mesmo a $-40^{\circ} \mathrm{C}$ ainda resta $9 \%$ da água em estado líquido. $\mathrm{O}$ produto $\mathrm{a}-5^{\circ} \mathrm{C}$ pode ser considerado congelado, mas ainda é necessário reduzir sua temperatura até valor próximo da temperatura da câmara de estocagem (entre $-18^{\circ} \mathrm{C} \mathrm{e}-30^{\circ} \mathrm{C}$ ) (CONTRERAS-GUZMAN,1982).

A velocidade de congelamento varia conforme o método adotado, o coeficiente de 
transferência térmica superficial e a embalagem. Em câmara com circulação de ar forçado, a velocidade é de $1 \mathrm{~mm} / \mathrm{h}$ e em congelador de túnel de 3 a $15 \mathrm{~mm} / \mathrm{h}$. Em congelador de placas a velocidade é de 12 a $25 \mathrm{~mm} / \mathrm{h}$, em ar forçado contínuo de 15 a $30 \mathrm{~mm} / \mathrm{h}$ e em congelamento por gases liquefeitos de 30 a 100 mm/h (INSTITUTO INTERNACIONAL DEL FRIO, 1990). A embalagem de sacos de polietileno com $0,015 \mathrm{~mm}$ de espessura permite o congelamento a $-25^{\circ} \mathrm{C} \mathrm{em} 3 \mathrm{~h} \mathrm{e}$ $30 \mathrm{~min}$, já as de cartão parafinado com $1 \mathrm{~mm}$ de espessura chegam a $-20^{\circ} \mathrm{C}$ em $5 \mathrm{~h}$ e $30 \mathrm{~min}$ (MCDONALD, 2001).

Dentre as desvantagens do congelamento lento estão a produção de grandes cristais de gelo nas células do pescado, podendo romper as paredes celulares e o aumento na concentração de sais e compostos químicos durante o congelamento que pode acelerar a autólise. Em temperaturas próximas de $0^{\circ} \mathrm{C}$ alguns tipos de bactérias podem se desenvolver e deteriorar o produto. No produto congelado lentamente há maior perda de fluido, ou seja, maior exsudação durante o descongelamento (CARNEIRO, 1999). Já no congelamento rápido, cristais muito pequenos são formados dentro e fora da estrutura celular e poucas mudanças são observadas. A desnaturação é limitada e ao retornar para temperatura ambiente o tecido muscular encontra-se em estado próximo ao original. Flutuações da temperatura de estocagem favorecem o crescimento de cristais de gelo e a aceleração de reações que reduzem a qualidade do produto, além de provocar maior liberação de líquidos (NEVES FILHO, 1992).

Segundo o INSTITUTO INTERNACIONAL DEL FRIO (1990) é difícil estabelecer padrão para tempo de congelamento para o pescado, porém, como regra geral, os peixes magros e de músculo branco mantém-se mais tempo com a qualidade máxima na câmara por 2 anos a $-30^{\circ} \mathrm{C}$.

As empresas brasileiras que trabalham com produtos congelados de pescado marinho colocam o produto no mercado geralmente congelado a $-35^{\circ} \mathrm{C}$, submetido ao congelador de placas ou túnel de ar frio, muitas das vezes em embalagens congeladas individualmente e em embalagens de caixas de papelão parafinado ou sacos plásticos. Predominam os camarões e os peixes como a merluza e a pescada, sendo que as lagostas congeladas e os camarões de excelente qualidade são destinadas à exportação (OETTERER, 2002).

Segundo BEIRÃO, TEIXEIRA e MEINERT, (2000) não há dificuldade em se congelar mexilhões com casca por período mais longo, porém tal procedimento torna-se antieconômico pelo substancial volume ocupado. A carne, depois de cozida e limpa, pode ser embalada de varias maneiras. Os tipos de embalagens mais utilizados são as caixas de papelão e os sacos plásticos, ou bandejas específicas para essa finalidade envoltas em filme retrátil, que permite a evacuação do ar e aumenta seu tempo de conservação. O produto também pode ser submetido diretamente ao processo de congelamento, sem embalagem individual, para só subseqüentemente ser embalado ou receber o glazeamento. $O$ mexilhão deverá ser congelado em temperatura máxima de $-27^{\circ} \mathrm{C}$ pelo período de 50 minutos e estocado a $-18^{\circ} \mathrm{C}$.

Esta pesquisa teve o objetivo de submeter mexilhões ao processamento por congelamento e posterior armazenamento congelado. Assim, as etapas de cocção prévia, desconchamento, embalamento e congelamento foram estabelecidas (padronizadas) mediante análises de qualidade para comercialização, conforme exigências da legislação. Esta pesquisa é parte do projeto de políticas públicas designado de "Diagnóstico e intervenções emergentes para comercialização de pescado - mexilhões no Litoral norte, região de Ubatuba, SP, para implantação de beneficiadora de mexilhões".

\section{MATERIAL E MÉTODOS}

\subsection{MÁTERIA-PRIMA}

Foram utilizados bivalves da espécie Perna perna, provenientes de criatórios da região de Ubatuba, SP. 


\subsection{COLETA DOS MEXILHÕES}

Foram coletados $40 \mathrm{Kg}$ de mexilhões e submetidos ao processo de desdobre, no qual são retirados do cacho e separados da fauna acompanhante. Após limpeza para a remoção de cracas e parasitas, os mexilhões seguiram para a lavagem com água do mar efetuando-se assim a higienização superficial das valvas.

Procedeu-se o acondicionamento dos mexilhões em embalagens de ráfia, sendo transportados em recipiente isotérmico contendo gelo na proporção de 3:1 (mexilhão/gelo). Não houve contato direto com o gelo para evitar a morte dos mexilhões.

\subsection{PROCESSAMENTO DOS MEXILHÕES}

O processamento ocorreu no Laboratório de Operações e Processos Unitários do Instituto de Tecnologia de Alimentos (ITAL), localizado em Campinas/SP, conforme o fluxograma da Figura 1.

\section{FIGURA 1 - FLUXOGRAMA DE PROCESSAMENTO E ANÁLISES DO MEXILHÃO}

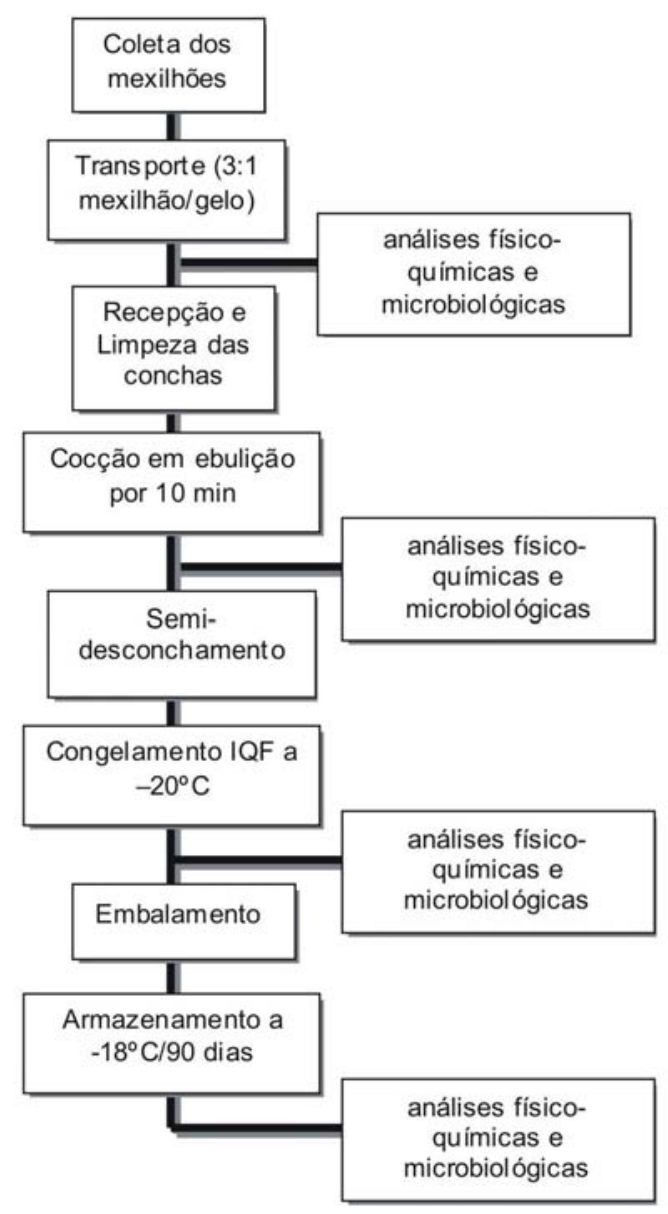

\subsubsection{Tratamento prévio-cocção}

Os mexilhões foram limpos, higienizados e passaram pelo processo de cocção por imersão em água em ebulição por 10 minutos, monitorados com o auxílio de conjunto de termopares até atingirem a temperatura de $96^{\circ} \mathrm{C}$. Após a cocção, os mexilhões foram semi-desconchados e os termopares fixados na região central das amostras. Essas foram transferidas para bandejas metálicas perfuradas e depois conduzidas para o congelamento. 


\subsubsection{Congelamento}

Os mexilhões foram congelados individualmente pelo método por ar forçado, com velocidade de $184 \mathrm{~m} / \mathrm{min}$, em câmara de congelamento a $-20^{\circ} \mathrm{C}$ da marca Kitfrigor, com capacidade de $3 \mathrm{~m}^{3}$. As bandejas foram colocadas na parte superior da câmara junto ao circulador de ar, na parte superior perto da porta da câmara e na parte inferior próximo da porta.

A temperatura de congelamento de cada bandeja foi monitorada com auxilio de 2 termopares (medidor de temperatura marca Ellab, modelo TM 9616) com sensores calibrados. Um foi inserido no interior das amostras e outro colocado na superfície da bandeja de acordo com a posição na câmara, num total de 6 termopares, designados de T1 a T6, especificamente: T1 = solto circulador (solto na bandeja próximo ao circulado); T2 = superior circulador (inserido na amostra/ prateleira superior próximo circulador); T3 = superior porta (inserido na amostra/prateleira superior próxima a porta), T4 = solto inferior (solto na bandeja na parte inferior); T5 = inferior porta (inserido na amostra/prateleira inferior próximo a porta) e T6 = câmara (temperatura interna do congelador). As leituras foram realizadas a cada $30 \mathrm{~s}$ com o auxílio do Software E-Vail Basic. Com o término do congelamento, as amostras foram embaladas em bandejas de isopor com filme de polietileno, seladas, identificadas e armazenadas em congelador a temperatura de $-18^{\circ} \mathrm{C}$ durante 90 dias.

\subsection{CÁLCULO DA VELOCIDADE DE CONGELAMENTO E CURVA DE CONGELAMENTO}

Os dados de temperatura e tempo de congelamento obtidos na leitura de cada termopar foram dispostos em tabelas, procedeu-se o cálculo da velocidade de congelamento e elaborou-se a curva de congelamento pela equação de PLANK (1963): $W=\delta / 2 T$, na qual $\delta=$ espessura do produto; $\mathrm{T}=$ tempo necessário para baixar a temperatura de $0 \mathrm{a}-5^{\circ} \mathrm{C}$, sendo $\delta=1,2 \mathrm{~cm}$.

\subsection{ANÁLISES FÍSICO-QUÍMICAS.}

As análises de umidade, proteína, lipídeos, cinza e carboidratos foram realizadas segundo a AOAC (1995). As determinação de frescor, bases nitrogenadas voláteis totais (BVNT), trimetilamina (TMA) e pH foram realizadas segundo metodologias oficiais do Ministério de Agricultura, Pecuária e Abastecimento (BRASIL 1981).

\subsection{ANÁLISES MICROBIOLÓGICAS}

As análises microbiológicas foram realizadas no Setor de Microbiologia de Alimentos do Departamento de Agroindústria Alimentos e Nutrição da Escola Superior de Agricultura Luiz de Queiroz (ESALQ-USP) em Piracicaba, SP.

\subsubsection{Preparo das diluições}

Foram transferidos $25 \mathrm{~g}$ de carne para copo de liquidificador estéril e $225 \mathrm{~mL}$ de solução salina peptonada $0,5 \%$. Homogenizou-se o material em liquidificador a $14.000 \mathrm{rpm}$ por $60 \mathrm{a} 120 \mathrm{~s}$ (VANDERZANT e SPLITTSTOESSER, 1992). Após moagem, as diluições decimais de $10^{-2}$ a $10^{-6}$ foram obtidas utilizando-se $10 \mathrm{~mL}$ da diluição anterior e $90 \mathrm{~mL}$ de solução salina peptonada $0,5 \%$.

\subsubsection{Microrganismos analisados nas amostras de mexilhão}

Foram realizadas contagens de Staphylococcus coagulase+ (LANCETTE e TATINI, 2001); Coliformes totais e fecais, utilizando a técnica de Número Mais Provável (APHA, 1998; HITCHINS 
et al., 2007); Salmonella (ANDREWS et al., 1992; BENNETT et al.,1999); Psicrotróficos e Vibrio parahaemolyticos (SILVA, JUNQUEIRA e SILVEIRA., 1997).

\subsection{ANÁLISE ESTATÍSTICA}

Os resultados obtidos foram analisados pelo programa estatístico SAS (1999). e as médias comparadas entre si pelo teste de Tukey, adotando-se o nível de significância de 5\%.

\section{RESULTADOS E DISCUSSÃO}

\subsection{CURVA DE CONGELAMENTO E VELOCIDADE DE CONGELAMENTO}

As curvas de congelamento apresentaram a forma geral típica (Figura 2), sendo compostas de 3 regiões. Na região de acomodação de temperatura acontece o resfriamento gradual da amostra, o platô corresponde à intensa formação de gelo (sobretudo entre zero e $-1,5^{\circ} \mathrm{C}$ ) e na terceira região ocorre queda brusca de temperatura (devido ao aumento da condutividade térmica da amostra já parcialmente congelada e ao menor calor específico).

\section{FIGURA 2-CURVAS DE CONGELAMENTO DOS MEXILHÕES}

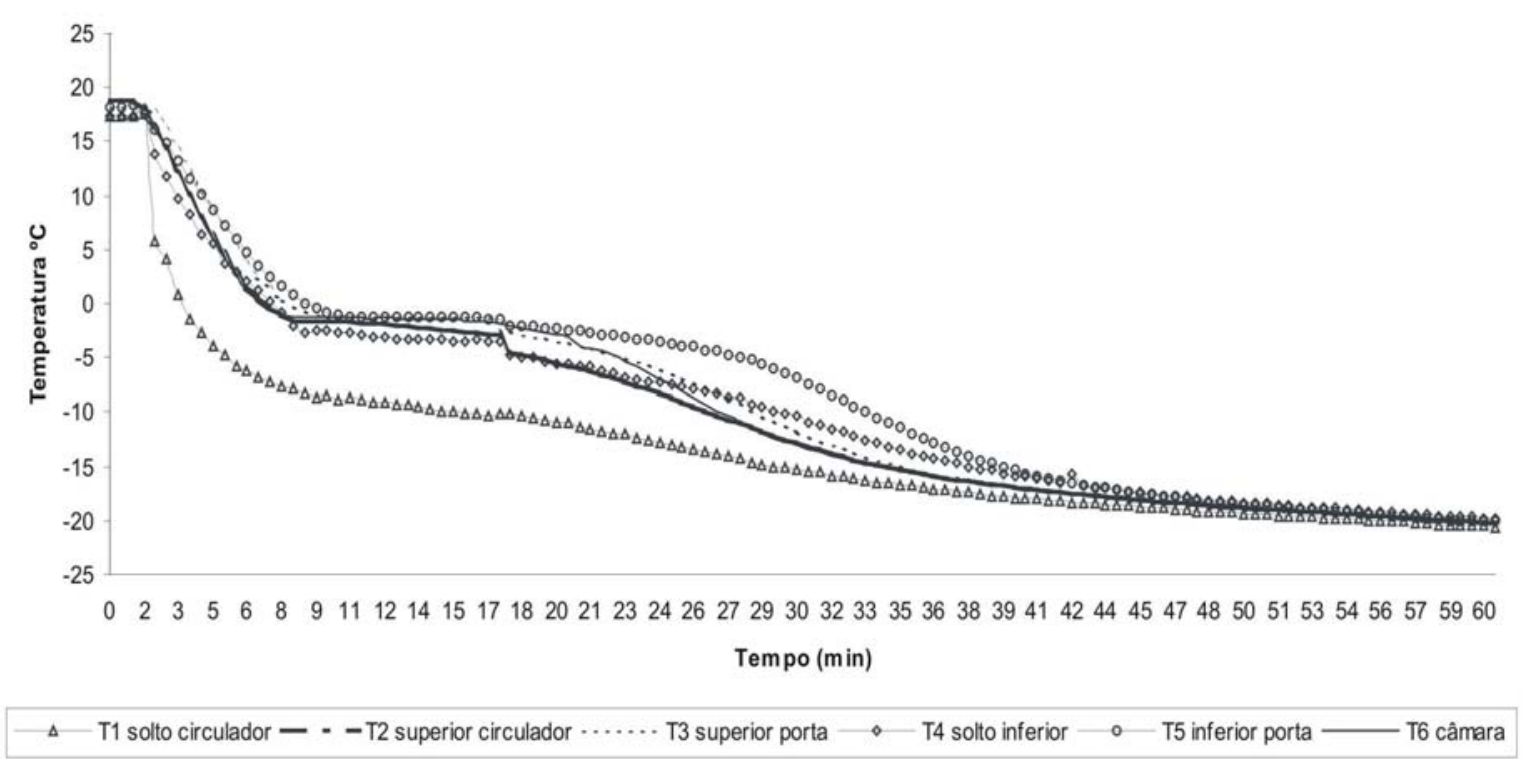

Em geral, a curva de congelamento é elaborada a partir do monitoramento da temperatura medida no centro do alimento. O ponto de congelamento, que varia conforme a espécie, os tecidos, a sazonalidade e a idade situa-se geralmente em torno de $-1,7$ a $-2,2^{\circ} \mathrm{C}$. O processo de formação de cristais de gelo ocorre no momento em que é liberado calor latente de solidificação de água. Em geral, desde o ponto de congelamento até a temperatura de $-5^{\circ} \mathrm{C}$ forma-se o maior número de cristais de gelo. Desta forma, essa faixa é denominada de zona de máxima formação de cristais de gelo (OGAWA e MAIA, 1999).

Segundo TANAKA et al. (1999), o ponto de congelamento para peixes de água doce, peixes marinhos (migrantes e demersais) e algas, situa-se em torno de $-0,5,-1,5$ e $-2,0^{\circ} \mathrm{C}$, respectivamente. 
As amostras de mexilhões semi-concha (Figura 2) atingiram a faixa de temperatura de $-20^{\circ} \mathrm{C}$ em aproximadamente $58 \mathrm{~min}$, com ponto de congelamento na faixa de zero a $-1,5^{\circ} \mathrm{C}$. A taxa de congelamento chegou a 95\%, o que significa que cerca de $90 \%$ da água livre foi congelada.

O ponto eutético do alimento, temperatura em que toda a sua água encontra-se congelada, é de aproximadamente $-60^{\circ} \mathrm{C}$. A água livre é quase completamente congelada em torno de $-30^{\circ} \mathrm{C}$, mas a água de constituição ainda não está em processo de congelamento (OGAWA e MAIA, 1999).

Os valores obtidos pelo cálculo da velocidade de congelamento variaram de 2 a $3,3 \mathrm{~cm} / \mathrm{h}$ para as amostras semi-desconchadas, devido à disposição das bandejas dentro da câmara (Tabela 1).

TABELA 1- TEMPO E VELOCIDADE DE CONGELAMENTO DOS MEXILHÕES

\begin{tabular}{lccc}
\hline Termopar & Amostras & $\begin{array}{r}\text { Tempo }\left(0 \mathrm{a}-5^{\circ} \mathrm{C}\right) \\
-----\min -----\end{array}$ & $\begin{array}{c}\text { Velocidade de congelamento } \\
------(\mathrm{cm} / \mathrm{h}) \text {----- }\end{array}$ \\
\hline T1 & solto circulador & 2,5 & 14,4 \\
T2 & superior circulador & 11,0 & 3,3 \\
T3 & superior porta & 14,3 & 2,6 \\
T4 & solto inferior & 11,5 & 3,2 \\
T5 & inferior porta & 18,3 & 2,0 \\
\hline
\end{tabular}

PLANK (1963) caracterizou o tipo de congelamento em $0,1 \mathrm{~cm} / \mathrm{h}$ para congelamento lento; $1-5 \mathrm{~cm} / \mathrm{h}$ para o congelamento de velocidade média e $>5 \mathrm{~cm} / \mathrm{h}$ para congelamento rápido. Portanto, a velocidade de congelamento dos mexilhões em câmara de ar forçado enquadrou-se na faixa de $1-5 \mathrm{~cm} / \mathrm{h}$ (caracterizado como congelamento de velocidade média).

Segundo o INSTITUTO INTERNACIONAL DEL FRIO (1990), os valores mais comuns encontrados na prática e seus respectivos processos são: $0,2 \mathrm{~cm} / \mathrm{h}$ (lento) para congelamento a granel em câmaras frias ventiladas, 0,5 a $3 \mathrm{~cm} / \mathrm{h}$ (rápido) para produtos embalados e congelados em câmaras de ar forçado ou em congeladores de placas, 5 a $10 \mathrm{~cm} / \mathrm{h}$ (rápido) para congelamento individual com produtos de pequenas dimensões como no sistema de leito fluidizado, e 10 a $100 \mathrm{~cm} / \mathrm{h}$ (ultra-rápido) para congelamento em "spray" e/ou imersão em gases liquefeitos.

\subsection{ANÁLISES FÍSICO-QUÍMICAS}

A Tabela 2 apresenta a composição química dos mexilhões in natura e processados.

TABELA 2- COMPOSIÇÃO CENTESIMAL DOS MEXILHÕES IN NATURA, PROCESSADOS E ARMAZENADOS DURANTE 90 DIAS

\begin{tabular}{cccccc}
\hline Tratamento & Umidade & Proteína & Lipídeos & Cinza & Carboidratos \\
\hline In natura & $-8^{\mathrm{a}}$ & $7,2^{\mathrm{a}}$ & $1,2^{\mathrm{b}}$ & $1,9^{\mathrm{a}}$ & $3,8^{\mathrm{a}}$ \\
Submetidos à & $81,0^{\mathrm{a}}$ & $7,5^{\mathrm{a}}$ & $1,5^{\mathrm{b}}$ & $1,9^{\mathrm{a}}$ & $8,1^{\mathrm{a}}$ \\
cocção & $84,2^{\mathrm{a}}$ & $7,3^{\mathrm{a}}$ & $1,5^{\mathrm{ba}}$ & $1,8^{\mathrm{a}}$ & $5,1^{\mathrm{a}}$ \\
Congelado & $83,0^{\mathrm{a}}$ & $7,5^{\mathrm{a}}$ & $1,6^{\mathrm{a}}$ & $1,8^{\mathrm{a}}$ & $6,2^{\mathrm{a}}$ \\
Armazenado & 2,05 & 0,23 & 0,16 & 0,05 & 1,58 \\
Desvio-Padrão & & & & & \\
\hline
\end{tabular}

Nota: médias seguidas pela mesma letra não diferem entre si ao nível de $5 \%$ de probabilidade. 
PORRELLI et al. (2003) avaliaram a composição centesimal de mexilhões Perna perna, coletados mensalmente de outubro/2002 a fevereiro/2003, em cultivo no Costão do Cedro em Ubatuba-SP. Encontraram para umidade 83,9\%, lipídeos 1\%, carboidratos 4\% e 1,9 de cinza.

Os valores médios obtidos para umidade, proteína, lipídeos, cinza e carboidratos do mexilhão in natura se aproximaram dos valores de 83; 12; 1,5; 1,9 e $3 \mathrm{~g} / 100 \mathrm{~g}$, respectivamente, constantes na tabela da ACAQ (2004) para o mesmo marisco.

SALAN (2005) obteve para mexilhões in natura da espécie Perna perna, valores médios de 82,82; 11,78; 1,55 e 2,37 g/100 g, respectivamente, para umidade, proteína, lipídeos e cinza.

Os teores médios de umidade obtidos nesta pesquisa para mexilhões in natura foram semelhantes aos encontrados por FURLAN (2004), 81,41 a 85,37 g/100 g; SALAN (2005), 82,82 g/ $100 \mathrm{~g}$ e MAGALHÃES (1986), 78,3 a 89,77 g/100 g, sendo superiores a 72,12 g/100 g citados por TAVARES et al. (1988).

Para o mexilhão cozido, o valor encontrado de umidade (81 g/100 g) aproximou-se dos valores obtidos por SCHRAMM (1993), entre 75 e 82 g/100 g, em mexilhões pré-cozidos em água fervente por 5 minutos. Já SALAN (2005) estudando mexilhões imersos em água em ebulição por 10 minutos encontrou $77,23 \mathrm{~g} / 100 \mathrm{~g}$.

Na base de dados de nutrientes do Departamento de Agricultura dos Estados Unidos consta que a espécie azul Mytilus edulis $L$. apresenta $81 \mathrm{~g} / 100 \mathrm{~g}$ de umidade in natura e $61 \mathrm{~g} / 100 \mathrm{~g}$ após cocção (USDA, 2007). Portanto, a variação no teor de umidade pode estar relacionada com o método de preparo ou metodologia de obtenção de amostras.

A Tabela 2 evidencia que após cocção ocorreu leve exsudação e diminuição do teor de umidade durante o congelamento, provavelmente pelo ligeiro acúmulo de água não-ligada no produto.

O teor médio de proteínas não evidenciou diferença significativa entre o mexilhão in natura, cozido, congelado e armazenado por 90 dias. GELLI (1992) encontrou teores de 6,7 a 9,58 g/ $100 \mathrm{~g}$ para mexilhões in natura. SALAN (2005) observou valores de proteína de 11,78 g/100 g para mexilhões in natura e 16,80 g/100 g para mexilhões cozidos por 10 minutos em ebulição. TAVARES et al. (1998) encontraram teores superiores para proteína, cerca de $20 \mathrm{~g} / 100 \mathrm{~g}$, o que pode ser explicado por diversos fatores como região de coleta, diferentes estádios de reprodução e metodologias utilizadas (MAGALHÃES, 1986).

Não foi verificada alteração no teor de proteína pelo processo de congelamento e armazenamento, fato que caracteriza os benefícios do congelamento na manutenção da qualidade nutricional dos mexilhões.

Os lipídeos não sofreram oscilações durante o processamento e armazenamento, cuja média geral para esse componente $(1,4 \mathrm{~g} / 100 \mathrm{~g})$ concorda com os resultados de FURLAN (2004) para a mesma espécie (valores entre 0,99 e 1,49 g/100 g). De acordo com ACKMAN (1999), o conteúdo em lipídeos de mariscos situa-se entre 1 e $2 \mathrm{~g} / 100 \mathrm{~g}$. Os bivalves armazenam suas reservas de energia na forma de glicogênio e não como gordura.

Não houve oscilação nos teores de cinza para os mexilhões in natura, cozido e congelado, estando a média geral para esse componente $(1,8 \mathrm{~g} / 100 \mathrm{~g})$ de acordo com a média geral de 1,79 g/ $100 \mathrm{~g}$ encontrada por FURLAN (2004).

Os teores de carboidratos encontrados variaram de 3,8 g/100 g para mexilhões in natura, 8,1 g/100 g para o cozido, 5,1 g/100 g para o congelado e 6,4 g/100 g após armazenamento de 90 dias, verificando-se relação inversa aos teores de umidade. Os resultados obtidos enquadraramse na faixa de 1,86 a 7,22 g/100 g para o mexilhão in natura, citada por FURLAN (2004). No entanto, mostraram-se superiores aos encontrados por SALAN (2005) entre 1,98 g/100 g para 0 mexilhão in natura e 1,87 para o mexilhão pré-cozido.

A Tabela 3 apresenta os teores de bases nitrogenadas voláteis totais, trimetilamina e pH dos mexilhões. 
Os valores encontrados para o pH estão de acordo com os dados de OETTERER (2002) e FURLAN (2004) para mexilhões in natura e de SALAN (2005) para mexilhões processados da mesma espécie, variando de 5,8 a 6,9; 6,14 a 7,2 e 6,87 a 7,11, respectivamente.

\section{TABELA 3 - BNVT, TMA E PH DOS MEXILHÕES IN NATURA, PROCESSADOS E ARMAZENADOS}

\begin{tabular}{|c|c|c|c|}
\hline \multirow{2}{*}{ Tratamento } & BNVT & & \multirow{2}{*}{$\mathrm{pH}$} \\
\hline & & & \\
\hline In natura & $4,3^{\mathrm{a}}$ & $2,0^{a}$ & $6,2^{b}$ \\
\hline Submetido à cocção & $5,0^{\mathrm{a}}$ & $0,6^{a}$ & $6,9^{a}$ \\
\hline Congelado & $4,0^{\mathrm{a}}$ & ND & $6,9^{a}$ \\
\hline Armazenado & $4,2^{\mathrm{a}}$ & $0,2^{\mathrm{a}}$ & $6,9^{a}$ \\
\hline Desvio-padrão & 0,9 & 1,2 & 0,3 \\
\hline
\end{tabular}

Médias seguidas pela mesma letra não diferem entre si em nível de 5\% de probabilidade.

Não houve alteração no valor do $\mathrm{pH}$ devido ao processamento ou durante o armazenamento. Os valores de $\mathrm{pH}$ de carne de pescado congelado têm provocado controvérsias. Autores citados por MILLS (1975) afirmaram que não há alteração no pH durante o armazenamento sob congelamento, enquanto outros defendem posição contrária. Para MILLS (1975), essas observações conflitantes não devem surpreender, uma vez que podem ocorrer reações que produzem ácidos e bases durante o congelamento.

Em estudo realizado por FURLAN (2004), entre os meses de novembro a março em Ubatuba com mexilhão Perna perna in natura, foram encontrados valores para BNVT de 5,6 mg/100 g a $11 \mathrm{mg} / 100 \mathrm{~g}$ e TMA de $0,6 \mathrm{mg} \mathrm{N} / 100 \mathrm{~g}$ a $7,7 \mathrm{mg} \mathrm{N} / 100 \mathrm{~g}$.

LAKSHMANAN, VARMA e IYER (1992), estudando peças de pescado congelado, encontraram incremento nos valores de BNVT durante o tempo de estocagem, o qual aumentava conforme a elevação da temperatura de estocagem.

A legislação brasileira vigente (BRASIL, 1980) determina que o pescado fresco deve apresentar níveis de TMA inferiores a 4 mg N/100 g. Já as legislações do Japão e da Austrália têm como limite $5 \mathrm{mg} \mathrm{N} / 100 \mathrm{~g}$ (JAY, 1994). Portanto, os valores de TMA encontrados nesta pesquisa estão de acordo com as legislações nacional e internacional.

Segundo REGENSTEIM et al. (1982) a habilidade dos microrganismos em elaborar TMA é diminuída pela estocagem em gelo e pelo $\mathrm{pH}$ reduzido, o que limita seu uso como indicador de qualidade. Nesta pesquisa verificou-se ausência de TMA no mexilhão congelado, conforme ilustra a Tabela 3.

\subsection{ANÁLISES MICROBIOLÓGICAS}

A Tabela 4 apresenta os resultados da análise microbiológica dos mexilhões.

Em moluscos in natura, as contagens totais de microrganismos referem-se ao conteúdo intravalvar carne-líquido e a população microbiana pode oscilar entre $10^{4}$ e $10^{6} \mathrm{UFC/g}$ (ICMSF, 1988; JAY, 1994).

A contagem de coliformes fecais para mexilhões in natura enquadrou-se no limite da legislação brasileira, Portaria no 451 do Ministério da Saúde (BRASIL, 1997), que estabelece como limite máximo de coliformes de origem fecal em pescado in natura, refrigerado ou congelado $10^{2} \mathrm{NMP} / \mathrm{g}$. Para moluscos bivalves submetidos à cocção e industrializados resfriados ou não, a Resolução no 12 de 02/01/01 da Agência Nacional da Vigilância Sanitária (ANVISA, 2001) admite limites máximos de $5 \times 10 \mathrm{NMP} / \mathrm{g}$ para coliformes fecais e $10^{3} \mathrm{UFC} / \mathrm{g}$ para Staphylococcus coagulase+. 


\section{TABELA 4 - MICRORGANISMOS EM MEXILHÕES IN NATURA, PROCESSADOS E ARMAZENADOS POR 90 DIAS}

\begin{tabular}{lcccc}
\hline \multicolumn{1}{c}{ Microrganismos } & Controle (In natura) & $\begin{array}{c}\text { Submetidos } \\
\text { à cocção }\end{array}$ & Congelado & Armazenado \\
\hline Coliforme Total (NMP/g) & $1,1 \times 10^{2}$ & 0,9 & 0,4 & 0,2 \\
Coliforme Fecal (NMP/g) & 9,3 & ausência & ausência & ausência \\
Salmonella sp (em 25 g) & Ausência & ausência & ausência & ausência \\
Staphylococcus coagulase+ & $7 \times 10^{1}$ & $10^{1}$ & $<1,0$ & $<1,0$ \\
(UFC/g) & $9,3 \times 10^{3}$ & $3,1 \times 10^{1}$ & $3,8 \times 10^{2}$ & $7 \times 10^{1}$ \\
Psicrotróficos (UFC/g) & $<1,0$ & $<1,0$ & $<1,0$ & $<1,0$ \\
V.parahaemolyticus (NMP/g) & & &
\end{tabular}

Com relação à qualidade microbiológica inicial dos mexilhões, Salmonella e Vibrio parahaemolyticus não foram isolados nas amostras. Quanto ao Staphyloocccus coagulase + , o valor encontrado para o mexilhão in natura foi de $7 \times 10^{1} \mathrm{NMP} / \mathrm{g}$ e a legislação admite no máximo $10^{3} \mathrm{UFC} / \mathrm{g}$.

De acordo com os padrões microbiológicos vigentes, os mexilhões utilizados como matériaprima nesta pesquisa apresentam boas condições sanitárias e estão seguros para o consumo.

A ICMSF (1992) recomenda à indústria de alimentos a utilização de matérias-primas com condições iniciais adequadas, pois falhas no processamento podem determinar a sobrevivência de microrganismos patogênicos de interesse em saúde pública.

Segundo HOBBS, ROBERTS e NASCIMENTO (1993) temperatura acima de $55^{\circ} \mathrm{C}$ é suficiente para destruir células vegetativas de Escherichia coli, Staphylococcus sp e Salmonella sp. Nesta, pesquisa o tratamento térmico aplicado aos mexilhões (10 min por imersão em água em ebulição) atingiu temperatura superior a $90^{\circ} \mathrm{C}$. As contagens obtidas no mexilhão após o tratamento térmico para coliformes totais diminuiram de $1,1 \times 10^{2} \mathrm{NMP} / \mathrm{g}$ para $0,9 \mathrm{NMP} / \mathrm{g}$, Staphyloccocus coagulase+ de $7 \times 10^{1} \mathrm{UFC/g}$ para $10^{1} \mathrm{UFC/g}$ e ausência de coliformes fecais após cocção. Assim, o processamento térmico utilizado foi eficiente para diminuir e/ou eliminar tais populações de microrganismos.

De acordo com PIGOTT e TUCKER (1990), os microorganismos patogênicos são destruídos em temperaturas abaixo de $100^{\circ} \mathrm{C}$ e o efeito de aumentar a temperatura interna dos alimentos para $66^{\circ} \mathrm{C}$ é suficiente para tornar o alimento seguro para o consumo.

A condição inicial dos mexilhões utilizados na etapa de congelamento foi atestada pela ausência de Salmonella e Vibrio parahaemolyticus, bem como pela redução de Escherichia coli após a cocção.

Com o processo de congelamento houve diminuição de 0,9 para 0,4 NMP/g de coliformes totais e redução dos Staphyloocccus coagulase+ para níveis não-detectáveis, que se mantiveram inalterados durante o armazenamento a $-18^{\circ} \mathrm{C}$ por 90 dias.

De acordo com JAY (1986), as bactérias do grupo coliforme podem crescer em temperaturas de $-2^{\circ} \mathrm{C}$ e temperaturas inferiores a $-5^{\circ} \mathrm{C}$ propiciam crescimento muito lento. Segundo OLSON e NOTTINGHAM (1988), microrganismos Gram-negativos (dentre os quais Escherichia coli) são mais sensíveis ao congelamento do que os Gram-positivos.

Como pode ser visto na Tabela 4, a contagem total de psicrotróficos de mexilhão in natura reduziu-se após a cocção em pelo menos 2 ciclos logaritmos. Após o congelamento verificou-se aumento de 1 ciclo logaritmo na contagem de psicrotróficos e nova redução de 1 ciclo logaritmo após o armazenamento, detectada após a condução do descongelamento.

Ao final do período experimental, as contagens de bactérias psicrotróficas nos mexilhões estavam abaixo dos níveis associados com a deterioração do pescado. Realmente, nenhum crescimento bacteriano deveria ser esperado nessas condições. Segundo HUSS (1988), a perda 
da qualidade do pescado ocorre quando as contagens de bactérias aeróbias na pele do peixe alcançam $10^{8}-10^{9} \mathrm{UFC} / \mathrm{g}$.

Os produtos pesqueiros frescos são altamente perecíveis e susceptíveis a deterioração causada pelo crescimento de bactérias psicrotrófilas. A estocagem desses produtos em gelo ou sob refrigeração durante a distribuição e comercialização resulta em pequeno prazo de validade, entre 5 a 10 dias (REDDY et al., 1996).

Segundo DAUDIN (1991), as bactérias psicrotróficas do gênero Pseudomonas e outros gêneros predominantes são altamente sensíveis ao congelamento e ao armazenamento.

O congelamento não destrói completamente a microflora do produto, mas o número de células viáveis é reduzido durante o processamento e a armazenagem. Imediatamente após o congelamento, a eficiência da eliminação de microrganismos varia de acordo com a espécie. As células que continuam viáveis logo após o congelamento vão, gradualmente, tornando-se inviáveis durante o armazenamento (SARANTÓPOULOS, OLIVEIRA e CANAVESI, 2001).

\section{CONCLUSÃO}

O congelamento dos mexilhões apresentou curva de congelamento típica, com ponto de congelamento situando-se na faixa de zero a $-1,5^{\circ} \mathrm{C}$, atingindo cerca de $95 \%$ de água livre congelada. A velocidade de congelamento variou de $2,0 \mathrm{~cm} / \mathrm{h}$ a $3,3 \mathrm{~cm} / \mathrm{h}$ devido a disposição das bandejas na câmara de congelamento.

Não houve alteração das características físico-químicas do produto pelo processo de cocção e congelamento.

Todas as amostras de mexilhão in natura atenderam aos padrões microbiológicos estabelecidos pela legislação brasileira. $O$ tratamento térmico foi efetivo no controle dos coliformes fecais, bem como reduziu as contagens de coliformes totais, Staphylococcus coagulase + e psicrotróficos.

O mexilhão congelado não apresentou Staphylococcus coagulase+ e a contagem de coliformes totais foi reduzida com o congelamento.

Esta metodologia do processamento e o monitoramento da qualidade podem ser adotadas pela indústria brasileira para produção de mexilhões congelados.

\section{ABSTRACT}

\section{THE QUALITY OF THE MUSSEL (Perna perna) SUBMITTED TO COMBINED PROCESSING OF COOKING, FREEZING AND STORAGE}

Mussels Perna perna cultivated and commercialized in the city of Ubatuba, SP (BRAZIL) were submitted to the processing by cooking, freezing and storage. The freezing point, freezing speed and freezing curves were determined in mussels without a part of the shell, being also evaluated the microbiological and physicochemical quality of the product. The processing of the mussel was started with the immersion in boiling water per 10 minutes allowing the withdrawal of the shells, being then, frozen IQF (Individually Quick Frozen), using the method of freezing by forced air. The curve of freezing of the mussel presented typical general form, with the freezing point placing itself around zero to $-1.5^{\circ} \mathrm{C}$, the freezing speed, varied from $2.0 \mathrm{~cm} \cdot \mathrm{h}^{-1}$ to $3.3 \mathrm{~cm} \cdot \mathrm{h}^{-1}$ as the disposal inside of freezing chamber. There was no changes on the physicochemical quality after cooking, freezing and storage processes. In relation to the microbiological quality, all the mussel samples in natura were between the microbiological standards established by the Brazilian legislation. Salmonella sp and Vibrio parahaemolyticus had not been isolated in none of the fresh mussel samples, cooked, frozen and stored. The thermal treatment controlled the fecal coliforms, as well as reduced the values of total coliforms counting. The frozen mussel did not present Staphylococcus aureus and the counting of total coliforms decreased. It was concluded that the processing of the mussel through cooking, freezing and storage assures the microbiological, and physicochemical quality of the product, which can be adopted as standard for the industry.

KEY-WORDS: MUSSEL - COOKING; FROZEN SPEED; FROZEN CURVE; FREEZING - STORAGE. 


\section{REFERÊNCIAS}

1 ACKMAN, R.G. Composición y valor nutritivo de los lipídios del pescado y del marisco. In: RUITER, A. El pescado y los productos derivados de la pesca: composición, propriedades nutritivas y estabilidad. Zaragoza: Acribia, 1999. Cap. 4. p. 81-121.

2 ANVISA. Agência Nacional da Vigilância Sanitária. Resolução- $R D C n^{\circ} 12$, de janeiro de 2001. Regulamento Técnico sobre padrões microbiológicos em alimentos. Dispinível em: http://www.anvisa.gov.br/e-legis/. Acesso em: 15 mar. 2007.

3 APHA. American Public Health Association. Standard methods for the examination of water and wastewater. $20^{\text {th }}$ ed. Washington, 1998. $937 \mathrm{p}$.

4 ANDREWS, W.H.; FLOWERS,R.S.; SILLIKER, J.; BAILEY, J. S. Salmonella. In: VANDERZANT, C. (Ed.). Compendium of methods for the microbiological examination of foods. $4^{\text {th }}$ ed. Washington: American Public Health Association, 1992. cap.25, p.371-415.

5 ACAQ. Associação Catarinense de Aquicultura. Valores nutricionais do mexilhão Perna perna e da ostra Crassostre gigas. Disponível em: http://www.acaq.org.br/valores_nutricionais.htm. Acesso em :06 dec. 2004.

6 AOAC. Association of Official Agricultural Chemists. Official methods of analysis of AOAC International. $16^{\text {th }}$ ed. Washington, 1995. v. 2

7 ASSUMPÇÃO, A. Estudo da viabilidade de criação de cooperativa dos produtores de mexilhões do litoral norte paulista. Piracicaba: ESALQ/Departamento Economia, Administração e Sociologia, 1999. 40 p. (Relatório CES, 629).

8 BEIRÃO, H.; TEIXEIRA, E.; MEINERT, E.M. Processamento e industrialização de moluscos. In: SEMINÁRIO E WORKSHOP TECNOLOGIAS PARA APROVEITAMENTO INTEGRAL DO PESCADO, Campinas, 2000 Anais... Campinas: ITAL/Centro de Tecnologia de Carnes, 2000. p.38-84.

9 BEN, A.M. Effect of freezing and microbial growth on myoglobin derivates of beef. Food Chemistry, v. 147, n. 10, p. 4093, 1999

10 BENNETT, A.R.; MACPHEE, S.; BETTS, R.; POST, D. Use of pyrrolidonyl peptidase to distinguish Citrobacter from Salmonella. Letters in Applied Microbiology, v.28, p.175-178, 1999.

11 BRASIL. Ministério da Agricultura. Regulamento da Inspeção Industrial e Sanitária de Produtos de Origem Animal (RIISPOA). Brasília, 1980. 165 p.

12 BRASIL. Ministério da Agricultura, Pecuária e Abastecimento e Secretaria Nacional de Defesa Agropecuária. Laboratório Nacional de Referência Animal. Métodos analíticos oficiais físico-químicos para controle de pescado e seus derivados. Brasília, 1981. cap 5 (Métodos quantitativos).

13 BRASIL. Ministério da Agricultura, Pecuária e Abastecimento. Regulamentos técnicos de identidade e qualidade de pescado e produtos de pesca. Brasília, 1997. 77 p. (série regulamentação técnica de identidade e qualidade de produtos de origem animal, 2).

14 CARNEIRO, M.J.M. Congelamento de filés de sardinha por imersão e avaliação física e sensorial de sua qualidade durante a estocagem. Campinas, 1999.135 p. Dissertação (Doutorado), Faculdade de Engenharia de Alimento, Universidade Estadual de Campinas.

15 CLUCAS, I. J. Fish handling, preservation and processing in the tropics. London: Tropical Products Institute, 1981. v.1. $85 \mathrm{p}$.

16 CONTRERAS-GUZMAN, E.S. Pescado e produtos marinhos. In: VAN DENDER, A.G.F. Armazenamento de gêneros e produtos alimentícios. São Paulo: Secretária de Indústria e Comércio, Ciência e Tecnologia, 1982. p.201-225.

17 DAUDIN, J.D. La congelación. In: GIRARD, J. P.(Ed). Tecnologia de la carne y de los productos cárnicos. Zaragoza: Acribia 1991. p. 1-33.

18 ESPÍNOLA, O.; DIAS, R.R.C. O Mexilhão como matéria-prima alimentar. ABIA/SAPRO, n.47, p.10-30, abr. 1980.

19 EPAGRI. Empresa de Pesquisa Agropecuária e Extensão Rural de Santa Cantarina S.A. Maricultura é prioridade para o governo federal. Disponível em: http://www.epagri.rct-sc.br/ Acesso em: 16 mar. 2007.

20 FAO. Food And Agriculture Organization. World fisheries production by capture and aquaculture, by country. Disponível em: http://www.fao.org/fi/website/FIRetrieveAction.do?dom=topic\&fid=3459. Acesso em: 15 mar. 2007.

21 FURLAN, E.F. Vida útil dos mexilhões Perna perna cultivados no litoral norte de São Paulo: aferição dos parâmetros físico-químicos e microbiológicos. Piracicaba, 2004108 p. Dissertação (Mestrado), Escola Superior de Agricultura Luiz de Queiroz" Universidade de São Paulo. 
22 FURTADO, A.A.L. Conservação de frutos do mar. In: SEMINÁRIO E WORKSHOP TECNOLOGIA PARA APROVEITAMENTO INTEGRAL DO PESCADO, 2000, Campinas. Anais... Campinas: ITAL, 2000. p.7-12.

23 GELLI, V.C. Aproveitamento de mexilhões: aspectos gerais Mollusca-Bivalvia. Fortaleza: Universidade Federal do Ceará, 1992. 98 p.

24 GEROMEL, E.J.; FORSTER, R.J. Princípios fundamentais em tecnologia de pescados. São Paulo: Governo do Estado de São Paulo, Secretaria da Indústria, Comércio, Ciência e Tecnologia e Coordenadoria da Indústria e Comércio, 1982.127 p.

25 HITCHINS, A.D.; FENG, P.; WATKINS, W.D.; ROPPEY, S.R.; CHANDLER, L.A. Escherichia coli and the Coliform bacteria. Disponível em: http://www.cfsan.fda.gov. Acesso em:15 mar. 2007.

26 HOBBS, B.C.; ROBERTS, D.; NASCIMENTO, M.A. Toxinfeccões e controle higiênico-sanitário de alimentos. São Paulo: Livraria Varela, 1993. 376 p.

27 HUSS, H.H. Fresh fish: quality and quality changes. Roma: FAO/DANIDA, 1988. p. 43-45.

28 INSTITUTO INTERNACIONAL DEL FRIO. Alimentos congelados-procesado y distribuición. Zaragoza: Acribia, 1990. $184 \mathrm{p}$.

29 IAL. Instituto Adolfo Lutz. Normas analíticas do Instituto Adolfo Lutz: métodos químicos e físicos para análise de alimentos. 3. ed. São Paulo, 1985. 533 p

JAY, J.M. Modern food microbiology. $3^{\text {rd }}$ ed. New York: Van Nostrand Reinhold, 1986. 642 p.

JAY, J.M. Microbiologia moderna de los alimentos. 3. ed. Zaragoza: Acribia, 1994. 804 p.

32 LAKSHMANAN, P. T.; VARMA, P.R.; IYER, T. S. G. Studies on the quality changes of frozen fish in retail cold stores. Food Science and Technology, v. 24, n.2, p. 190, 1992.

33 LANCETTE, G.A.; TATINI, S.R. Staphylococcus aureus. In: DOWES, F.P.; ITO, K. (Ed.). Compendium of methods for the microbiological examination of foods. $4^{\text {th }}$.ed. Washington: APHA, 2001. p. 387-403.

34 MAGALHÃES, A.R.M. Teor de proteína do mexilhão Perna perna (Linné, 1957) (Molusca - Bivalvia) em função do ciclo sexual. São Paulo, 1986. 117 p. Dissertação (Mestrado), Instituto de Biociências, Universidade de São Paulo. McDONALD, I. Freezing small pelagic fish. Torry Advisory Note, Edinburgh, n. 75, p. 8, 2001.

MILLS, A. Measuring changes that occur during frozen storage of fish: a review. Journal of Food Technology, v. 10, n. 5, p. 483-496, 1975.

37 NEVES FILHO, L.C. Refrigeração na indústria de alimentos. Campinas: UNICAMP, 1992. 176 p. OETTERER, M. Industrialização do pescado cultivado. Guaíba: Editora Agropecuária, 2002. 200 p. OGAWA, M.; MAIA, E.L. Manual de pesca: ciência e tecnologia do pescado. São Paulo: Varela, 1999. v.1. 430 p. OLSON, J.C., NOTTINGHAM, P.M. Temperatura. In: ICMSF. International Comission on Microbiological Specifications For Foods. Ecologia microbiana de los alimentos: productos alimenticios. Zaragoza: Acribia, 1988. p.1-38.

41 PIGOTT, G.M.; TUCKER, B.W. Seafood- effects of technology on nutrition. New York: Marcel Dekker, 1990. p. $104-135$.

42 PLANK, R. Empleo del frio en la industria de la alimentacion. Barcelona: Editorial Reverté, 1963.805 p.

43 PORRELLI, P.; GALVÃO J.A; FURLAN, E.F. et al. Interferência das características biométricas na composição centesimal de mexilhões Perna perna (L). In: SIMPÓSIO INTERNACIONAL DE INICIAÇÃO CIENTÍFICA DA UNIVERSIDADE DE SÃO PAULO, 11, 2003, Piracicaba. Anais... Piracicaba: Escola Superior de Agricultura "Luiz de Queiroz", 2003. v. 11.

44 REDDY, N. R.; PARADIS, A.; ROPMAN, M. G.; SOLOMON, H. M.; RHODEHAMEL, E. J. Toxin development by Clostridium botulinum in modified atmosphere-packaged fresh tilapia fillets during storage. Journal of Food Science, v. 61, n. 3, p. 632-635, 1996.

45 REGENSTEIN, J. M.; SCHLOSSER, M. A.; SAMSON, A.; FEY, M. Chemical changes of trimethylamine oxide during fresh and frozen storage of fish. In: MARTIN, R.E.; FLICK, G. J.; HERBERD, C.E.; WARD, D. R (Ed). Chemistry \& biochemistry of marine food products. Westport: Avi Publishing, 1982. p.137-147.

46 SALAN, E. O. Tratamento térmico de mexilhões Perna perna como forma de assegurar a qualidade: valiação do crescimento de Bacillus cereus e de Staphylococcus aures. Piracicaba, 200588 p. Dissertação (Mestrado), Escola Superior de Agricultura Luiz de Queiroz, Universidade de São Paulo.

47 SARANTÓPOULOS, C. I. G. L.; OLIVEIRA, L. M.; CANAVESI, E. Requisitos de conservação de alimentos em embalagens flexíveis. Campinas: CETEA/ITAL, 2001. 213 p. 
SAS Institute. SAS user's guide: statistics (software). Version 8.0. Cary, 1999.

49 SCHRAMM, M.A. Caracterização e aproveitamento de mexilhões Perna perna (Linné, 1758). Porto Alegre, 1993. 54 p. Monografia (Graduação), Faculdade de Engenharia de Alimentos, Universidade do Rio Grande do Sul.

50 SILVA, N. da; JUNQUEIRA, V.C.A; SILVEIRA, N.F. de A. Manual de métodos de análises microbiológicas de alimentos. São Paulo: Varela, 1997. 295 p.

51 SILVA, J.A. Tópicos da tecnologia dos alimentos. São Paulo: Varela, 2000. 227 p.

52 TANAKA, T. Marine products in Japan, 1. In: MANUAL de pesca: ciência e tecnologia do pescado. São Paulo: Varela, 1999. v.1.p. 258-270.

53 TAVARES, M.; SABRIA, A.; BACETTI, L.B. et al. Métodos sensoriais, físicos e químicos para análise de pescado. In: SEMINÁRIO SOBRE CONTROLE DE QUALIDADE NA INDÚSTRIA DE PESCADO, 1988, Santos. Anais... Santos: Instituto de Pesca, 1988. p.117 -134.

54 USDA. United States Department of Agriculture. Base de dados de nutrients. Disponível em: http://www.unifesp.br/dis/ servicos/nutri. Acesso em: 15 mar. 20

55 VANDERZANT, C.; SPLITTSTOESSER, D. F. Compendium of methods for the microbiological examination of foods. $3^{\text {rd }}$.ed. Washington: APHA, 1992. cap. 25. 1219 p. 